\title{
Segmentation of Young Adult Consumers in China: A Global-local Cultural Identity Perspective
}

\author{
Chunling $\mathrm{Yu}^{1} \&$ Lily C Dong ${ }^{2}$ \\ ${ }^{1}$ School of Economics and Management, Tsinghua University, Beijing, 100084, P.R. China \\ ${ }^{2}$ School of Management, University of Alaska Fairbanks, Fairbanks, Alaska, USA \\ Correspondence: Lily C Dong, School of Management, University of Alaska Fairbanks, PO Box 756080, \\ Fairbanks, AK 99775-6080, USA. E-mail: lily.dong@alaska.edu
}

Received: October 5, 2018 Accepted: November 30, $2018 \quad$ Online Published: January 11, 2019

doi:10.5539/ijms.v11n1p30 URL: https://doi.org/10.5539/ijms.v11n1p30

\begin{abstract}
This study explores the segmentation of young adult consumers in the growing market of China by adopting the cultural identity theory about global-local identity beliefs (global citizenship through global brands, nationalism, and consumer ethnocentrism). We use cluster analysis to outline individuals on their integration of three cultural beliefs. Then we examine each cluster for their attitude toward advertisements of global brands with global consumer cultural positioning (GCCP) and local consumer cultural positioning (LCCP). We identified four segments: the glocal citizen (37\%), the explorer (26\%), the extremely nationalist (19\%) and the global-viewed adaptor (18\%). All four segments demonstrate different attitudes to GCCP and LCCP advertisements and different purchasing intentions on global brands using GCCP and LCCP strategies.
\end{abstract}

Keywords: global-local cultural identity, segmenting, consumer cultural positioning

\section{Introduction}

The young adult consumer group is an attractive segment for multinational companies, particularly in emerging markets (Douglas \& Craig, 2006; Kjeldgaard \& Askegaard, 2006; Strizhakova, Coulter, \& Price, 2012). This cohort has higher exposure to global media and technology, and is more likely to be familiar with the concept of branding (Lambert-Pandraud \& Laurent, 2010; Batra, Ramaswamy, Alden, Steenkamp, \& Ramachander, 2000; Holt, Quelch, \& Taylor, 2004; Zhou, Yang \& Hui, 2010). This cohort was often perceived as a relatively homogeneous segment that welcomes global brands, therefore, multinational firms and global brands attempted to attract young people using global culture positioning. However, consumer culture research documents that this cohort is less settled in their identity and more open to sharing varied beliefs and behavioral practices with certain global and local cultural communities (Jensen, 2011; Kjeldgaard \& Askegaard, 2006). That is, the young adults are more heterogeneous in their attitudes and beliefs related to globalization (Kjeldgaard \& Askegaard, 2006), and individuals develop a global-local (glocal) cultural identity that reflects their beliefs about both global phenomena and local culture (Strizhakova et al., 2012).

Strizhakova and his coauthors define glocal cultural identity as the coexistence of a broad range of beliefs and behaviors embedded to varying degrees in both local and global discourses (Strizhakova et al., 2012). They point out that because global and local orientations can conflict, an individual's glocal cultural identity may account for the different and even opposing demands resulting from the processes of globalization and localization. Glocal cultural identity includes three beliefs. The first reflects the influence of globalization, i.e., the belief in global citizenship through global brands (Steenkamp, Batra \& Alden, 2003; Strizhakova, Coulter, \& Price, 2008). The other two beliefs reflect dialogical influences of localization: nationalism (Dong \& Tian, 2009; Douglas \& Craig, 2011; Varman \& Belk, 2009) and consumer ethnocentrism (Shimp \& Sharma, 1987). Nationalism embodies the salience of one's nation and local culture, while consumer ethnocentrism embodies the preferences for locally-produced brands and products.

Our research goal is to segment young adult consumers based on these three glocal cultural identity beliefs (belief in global citizenship through global brands, nationalism, and consumer ethnocentrism) in the emerging market of China. We would like to know whether: 1) they are globally-oriented as stereotyped by most of companies, 2) they are more engaged with the new concept of glocal orientation as argued by some researchers, 
or 3) there are other types of cultural engagement hidden in the targeted research market. To discover the various degrees of cultural engagement of young adult consumers, we use cluster analysis to profile individuals on their glocal cultural identity as an integration of their beliefs about global citizenship through global brands, nationalism, and consumer ethnocentrism. Next, in relation to these profiles, we assess the following specific consumer branding practices: 1) consumers' attitude toward advertisements of global brands on different consumer cultural positioning, especially on global consumer cultural positioning (GCCP) and local consumer cultural positioning (LCCP). 2) Consumers' purchase intention on global brands with GCCP and LCCP strategies. We focus on the emerging markets of China for several reasons: first, China, as the largest emerging market economy, has received increasing attention in consumer research. Second, China has been changing continuously from a planned economy to a market economy in the past decades (Child \& Tse, 2001). The unique situation of China's reform over the last three decades offers us a rare opportunity to study the effects of social-economic transitioning on consumers' global-local cultural identity and consumption behavior.

This study makes two important contributions to a better understanding of the consumption practices of young adult consumers in the emerging markets, with implications for global and local brand management. First, we focus on the examination of young adult consumer segmentation in emerging market of China. This cohort is considered as one of most attractive target markets by multinational firms and global brands, yet little research has been conducted regarding its further segmentation (Douglas \& Craig, 2011). Results of our data analysis indicate there are four distinct segments, which suggest that multinational and local companies need to be cognizant of the complex and dynamic nature of global-local cultural identity among the young adult cohort in emerging markets. Second, we further examine each segment's attitude towards advertisements with different consumer cultural positioning. Specifically, we extend prior research on consumer attitudes toward global and local products (Steenkamp \& de Jong, 2010) to examine differences in consumer response to advertisements reflecting a global consumer culture positioning (GCCP) versus a local consumer culture positioning (LCCP) and purchase intensions. The results demonstrate that advertisements of global brands with GCCP and LCCP are nomologically different and evaluated differently by the segments.

In the following section, we begin with a review of previous research related to cultural identity formation among young adults in the age of globalization, and consumer cultural positioning theory. We present the research methodology, analysis and results, and a brief discussion of the results. We close with a more general discussion, identify managerial implications, and suggest directions for further research.

\section{Theoretical Foundation}

\subsection{Young Adult Consumers in China}

The term "young adult" is generally defined as a person who has not yet grown up (socially and financially) but is too old and mature to be considered a child. They can be 18 years or older yet still dependent on parents financially. A generational cohort refers to a consumer segment that uses a consumer's coming-of-age year as a proxy to postulate his or her value priorities developed through life experiences during his or her formative years, which may persist throughout that person's lifetime (Hung, Gu, \& Yim, 2007).

After China's adoption of open policy in 1978, numerous foreign firms have made investments in the country as they were attracted by its huge market size and great potential. After Deng Xiaoping's tour to southern China in 1992, foreign direct investment increased fivefold over the next decade. This wave of investors included firms from Europe, Asia, and the US, and ensured the presence of global brands in China (Hung, Gu, \& Yim, 2007). Therefore, we focus on the young adults, whose coming of age happened during the early 1980s and middle 1990s, and grew up in a society whose economy was transitioning from a centrally planned system to a market system that stressed competition, entrepreneurship, and individual accomplishment. This cohort includes college students, and young professionals. Unlike other generations, this group obtained a good education during their primary life. Good education background helps form their core value and personal competency. Hence they are confident in their ability to accomplish goals. In addition, this age group seeks diversity and has a high tolerance for differently held beliefs (Hermans \& Dimaggio, 2007). They are aware of growing up in a culturally complex world. And since they are addicted to social media, it is common for them to surf on the internet to learn about various cultures (Fong, 2004). Eventually, their background drives them to aspire to travel and experience the world. Young adult consumers in emerging markets are strongly impacted by the media especially from the US and UK entertainment industry. Their education, exposure to western culture through social media and traveling, would influence the consumption behaviors of young adult consumers in China, especially in big cities like Beijing and Shanghai. China was integrating into the global community, so its members developed tastes in fashion and products similar to those of youths around the world (Arnett, 2002). 
Previous studies have shown that many consumers in the emerging markets prefer global and foreign brands, which are often of better quality and reputation in comparison with local brands (Batra et al., 2000; Steenkamp et al., 2003). Many consumers in these markets such as China, especially the emerging upper class, do prefer and purchase/own foreign brand products. Therefore many multinational companies have achieved their high sales goal in these emerging markets by enhancing global brand image (Steenkamp \& de Jong, 2010; Zhou, Yang, \& Hui, 2010). However, multinationals are losing ground to domestic producers as a result of the effort of host government to help local businesses and the rising nationalism in these countries. On the one hand, local manufacturers have improved product quality and become more sophisticated at marketing their brands. On the other hand, many multinational companies, especially those with joint venture partners in China, are often reluctant to transfer advanced product technologies to China for fear of losing their intellectual property rights (Zhang, Li, Hitt, \& Cui, 2007).

Therefore, as China was opened to foreign investors in a gradual process, region by region and industry by industry, over the course of thirty years, globalization and localization have become co-dependent. While global brands promote discourses of global citizenship and culture in their marketing campaigns, they simultaneously fuel the growth of national pride and support for local manufacturers (Douglas \& Craig, 2011).

\subsection{Young Adult Glocal Cultural Identity Segmentation}

Approaching from the consumer identity perspective, Arnould and Thompson (2005) conceptualize consumer culture theory as the process by which consumers actively appropriate and contextualize the symbolic meanings encoded in marketer-generated goods to construct individual and collective identities. The premise in this theoretical perspective is that the marketplace provides consumers with cultural and mythic resources to use to personalize cultural scripts that align with their identities (Özsomer \& Altaras, 2008). That is, the central notion of consumer culture is that in a modern world, core identities are defined and oriented in relation to consumption (Holt, 2002).

With increasing globalization, many consumers are becoming members of multiple sociocultural contexts and hold multiple social identities, which in turn influence their attitudes and decisions (Arnett, 2002). It is widely recognized that the interpenetration of local cultures and the cultural forces associated with the globalization of the marketplace heavily influence contemporary consumer culture (Coulter, Price, \& Feick, 2003). A growing body of research suggests that in response to globalization, many consumers strive to integrate their local identities with global citizenship, exhibiting some form of a "glocal" identity (Arnett, 2002; Kjeldgaard \& Askegaard, 2006; Steenkamp \& de Jong, 2010). Being local means identifying with people in one's local community, whereas being global means identifying with people around the world.

Strizhakova et al. (2012) evaluate the glocal cultural identity of the young adult cohort in the emerging markets of Russia and Brazil by considering the theory's grounding in three global-local identity beliefs. They suggest that one belief fueled by globalization (global citizenship through global brands) and two beliefs fueled by dialogically-opposed localization (nationalism and consumer ethnocentrism) as a basis for examining glocal cultural identity. Specifically, global citizenship through global brands is a belief reflective of the global dimension of glocal cultural identity. In contrast, nationalism and consumer ethnocentrism are beliefs reflective of the local dimension of glocal cultural identity. They further investigate the understudied young adult cohort in the emerging markets of Russia and Brazil and segment this cohort on their global-local identity beliefs. Segmenting the young adult cohort based on these beliefs resulted in the identification of four segments across Russian and Brazilian samples: Globally-engaged, Glocally-engaged, Nationally-engaged, and Unengaged. Their research provides an opportunity to speculate how glocal cultural identity takes shape and transforms over time as an individual negotiates between global and local cultures (Arnett, 2002; Eckhardt, 2006; Jensen, 2011).

The unique situation of China's reform over the last three decades offers us a rare opportunity to study the effects of social-economic transitioning on consumers' global-local cultural identity and consumption behavior. The young adult cohort is particularly worthy of investigation, as they are less settled in their identity and more open to sharing varied beliefs and behavioral practices with certain global and local cultural communities (Jensen, 2011; Kjeldgaard \& Askegaard, 2006). We will follow the study of Strizhakova et al. (2012) to explore the evolving and transformation of glocal cultural identity of young adult cohort in China.

\subsection{Attitude Toward Advertisements with GCCP and LCCP}

Alden, Steenkamp, \& Batra (1999) identify three positioning strategies for brands in an international context. Global consumer culture positioning (GCCP) strategy is defined as a strategy that identifies the brand as a symbol of a given global culture. International advertising plays an important role in communicating these symbols associated with a given culture (Akaka \& Alden 2010). In contrast, local consumer culture positioning 
(LCCP) strategy is defined as a strategy that associates the brand with local cultural meanings and that reflects the local culture's norms and identities. A third positioning strategy is foreign consumer culture positioning (FCCP), where the brand is associated with a specific foreign culture. As very few advertisements use a foreign consumer culture positioning (Alden et al., 1999), we focus only on global and local consumer culture positioning in our study, hereafter referred to as GCCP and LCCP.

Advertising is an important tool for companies to promote their products and expand their customer base. The psychology basis of advertising is mostly involved with visual appeals and message themes, though not often entirely based on truth, to impact consumers' perception of the brand and stimulate consumers' emotional desire for the products or service. Our study on young adult segments' attitude towards different advertisements will help us gain more understanding about how young adult consumers form preference for GCCP advertisements versus LCCP advertisements by the same global brands and how it (the preference) affects their purchasing decision.

\section{Research Methodology}

\subsection{Sample and Procedure}

In general, the age range of young adults is accepted as between 21-36 years, they came of age during the early 1980s and middle 1990s. Undergraduate and MBA students from a public university in Beijing, China, were recruited to participate in our study ( $\mathrm{n}=297$, average age $=23.5,50 \%$ females), and a lottery for monetary prizes was offered. This sample was chosen for two reasons: first, because students in Beijing usually come from all over the country, the sample holds a good representation of Chinese young-adult in the whole country. Second, students in these universities normally are from well-off families that provide them the funding to go abroad, master a foreign language and be exposed to diverse media to try and get the sense of international and domestic products.

Participants completed a pencil and paper survey which included consumer travel history, demographic variables, and measures of three global-local identity beliefs: belief in global citizenship through global brands, consumer ethnocentrism, and nationalism. All respondents are presented with two print ads of a global brand, one is GCCP and the other is LCCP, and fill out a survey on attitudes towards these two advertisements, as well as their purchase intention. It took approximately 10-15 minutes to finish the questionnaire.

We first conducted a pilot study to select the brands and advertisements. We selected the top three product categories and brands that the pilot participants had listed down: soft drinks (Coca Cola), smart phone (Samsung) and sneakers (New Balance). Then we selected 6 different advertisements, 3 for global positioning and 3 for local positioning. The advertisements were preselected based on the product category and brand that young adults are interested in. As a point of reference to ensure the selected advertisements were correctly classified as having a global and local positioning (GCCP and LCCP), we had checked by asking participants to view the selected advertisements and indicated their level of certainty of this categorization. The results confirmed that respondents distinguished all advertisements correctly as GCCP and LCCP.

We divide the advertisements into three different sets. Each set comprises of one GCCP and one LCCP advertisements. Three different sets of advertisement were combined randomly into the second part of the questionnaire in order to reduce the chance of bias due to the specific reasons that respondents may have to the selected advertisement.

\subsection{Measures}

We adopted the measures used from prior studies (Strizhakova et al., 2012), in which the scales showed high reliability by using seven-point Likert-type scales to measure the three cultural identity beliefs. To measure consumer attitudes toward GCCP and LCCP advertisements, we adopted an item from Wells's (1964) emotional quotient scale and reaction profile and Feltham's (1994) the persuasive inventory disclosure scale to account for emotions (Unattractive/ attractive, uninteresting/ interesting, Boring/ fascinating, not worth looking/ worth looking, and not funny/ funny). Finally, we included the question "Would you like to buy this product?" to assess the impact of consumer cultural positioning toward consumers' purchasing intention after viewing the GCCP and LCCP advertisings, respectively.

\section{Analysis and Results}

We analyzed the data in three phases. First, we conducted a preliminary analysis to assess the quality of response and the internal reliability for the constructs. Then we used factor analysis to examine the items in the first part of questionnaires. Second, we used the three components from factor analysis to run hierarchical and K-means cluster analysis in order to segment our participants on their cultural beliefs in China. Last, we estimated each 
segment's profile regarding its attitude toward GCCP and LCCP advertisement and purchase intention.

\subsection{Glocal Cultural Identity Segment}

All the constructs of this study had Cronbach's Alpha reliability coefficients in excess of 0.80 . It indicates that all the constructs have good internal validity and indeed measure the same construct. We have conceptualized the variables in the questionnaire and got three components by using factor analysis. We report the factor analysis results in table1.

Table 1. Construct indicator, factor loadings, means, and reliabilities $(\mathrm{n}=297)$

\begin{tabular}{ll}
\hline Belief in global citizenship through global brands (Mean, Cronbach's alpha) & $(3.32,0.65)$ \\
Buying global brands makes me feel like a citizen of the world. & 0.835 \\
Buying global brands gives me a sense of belonging to the global marketplace. & 0.866 \\
Purchasing global brands makes me feel part of something bigger. & 0.561 \\
Nationalism (Mean, Cronbach's alpha) & $(5.65,0.61)$ \\
China has a strong historical heritage. & 0.674 \\
Chinese citizens are proud of their nationality. & 0.629 \\
Chinese citizens possess certain cultural attributes that people of other countries do not possess. & 0.757 \\
One of the things that distinguishes Chinese from other countries is its traditions and customs. & 0.618 \\
Consumer ethnocentrism (Mean, Cronbach's alpha) & $(2.62,0.71)$ \\
Purchasing foreign-made products is not Chinese. & 0.678 \\
It is not right to purchase foreign-made products because it puts fellow Chinese out of jobs. & 0.771 \\
Chinese consumers who purchase products made in other countries are responsible for putting their fellow & 0.714 \\
Chinese out of work. & 0.730 \\
We should purchase products manufactured in China instead of letting other countries get rich of us. & \\
\hline
\end{tabular}

Then we used these three components (also called global-local identity belief factors) to segment our young adult participants. We began with hierarchical cluster analysis and found the three distinct clusters. We continue a K-means cluster analysis with three clusters and four clusters, and found that the segments of both three-cluster type $(\mathrm{F}(\mathrm{G})=179.047, \mathrm{~F}(\mathrm{~N})=175.376, \mathrm{~F}(\mathrm{E})=13.807, \mathrm{p}<0.001)$ and four-cluster type $(\mathrm{F}(\mathrm{G})=95.159, \mathrm{~F}(\mathrm{~N})=93.038$, $\mathrm{F}(\mathrm{E})=105.457, \mathrm{p}<.001)$ differed significantly on our three factors. We have examined the attribute of each segment of three-cluster type and four-cluster type and discovered that the four-cluster type represents more distinct in cultural identity beliefs than the three-cluster type. Therefore, we decided to segment our Chinese participants in this study into four-cluster type. We reported the cluster analysis results in table 2.

Table 2. Cluster analysis: total number of cluster, mean, and F-value

\begin{tabular}{|c|c|c|c|c|c|}
\hline & $\begin{array}{l}\text { (1) } \\
\text { Explorer }\end{array}$ & $\begin{array}{l}(2) \\
\text { Global-viewed } \\
\text { Adaptor }\end{array}$ & $\begin{array}{l}\text { (3) } \\
\text { Glocal Citizen }\end{array}$ & $\begin{array}{l}\text { (4) } \\
\text { Extremely } \\
\text { Nationalist } \\
\end{array}$ & F-value \\
\hline Factors & $\begin{array}{l}n=76 \\
(26 \%)\end{array}$ & $\begin{array}{l}\mathrm{n}=54 \\
(18 \%)\end{array}$ & $\begin{array}{l}n=109 \\
(37 \%)\end{array}$ & $\begin{array}{l}\mathrm{n}=58 \\
(19 \%)\end{array}$ & \\
\hline $\begin{array}{l}\text { Belief in global citizenship } \\
\text { through global brands }\end{array}$ & 2.82 & 3.70 & 4.07 & 2.22 & $95.159 * * *$ \\
\hline Nationalism & 5.49 & 4.47 & 6.15 & 6.03 & $93.038 * * *$ \\
\hline Consumer Ethnocentrism & 1.60 & 3.39 & 2.56 & 3.32 & $105.457 * * *$ \\
\hline
\end{tabular}

The first segment holds low scores in all three global-local identity belief, we describe it as Explorer; the second segment holds high score in consumer ethnocentrism and high score in global identity belief, we call it Global-viewed adaptor; the third segment holds high scores in both global identity belief and nationalism, we describe it as Glocal citizen; the last segment holds high scores in both nationalism and consumer ethnocentrism, we call it Extremely nationalist.

The explorer segment, representing $26 \%$ of participants and can be described as a segment that is not distinct in either global or local identity belief comparing to other clusters; however they are proud of the nation but they are indifferent in either utilizing global or local brands. It is possible that they are generally not interested in consumption and tend to purchase the products that are available in the convenient marketplace. It can be 
elaborated that this segment denies engaging in any specific cultural identity, and brands' country-of-origin has no influence on them. It is a segment that "shows no concern for brands and thinks for themselves" or "in a soul searching period". Therefore, they are willing to explore and try new things that are not too far from their reach. The Global-viewed adaptation segment, representing $18 \%$ of participants and can be described as a segment that is conscious of using domestic products; however, they are open for global culture or trying new products. This segment need time to adapt themselves to the world culture and find the way to use world product to fit their beliefs and needs. The glocal citizen segment, representing $37 \%$ of participants and can be described as a segment that proud of their nation and hold an understanding of international sense. This means members of this segment are adaptable to globalization, simultaneously are able to interplay both culture to express their individuals. This segment is the biggest among the four segments. The extremely nationalistic segment, representing $19 \%$ of participants and can be described as a segment that is very patriotic since they hold a strong sense of nation pride and are likely to consume only locally-made products. A global experience is required to lift up an international spirit.

\subsection{Attitude Toward GCCP and LCCP Advertisements}

We report the clusters attitude toward GCCP and LCCP advertisements in table 3. The glocal citizen segment is the biggest segment of Chinese young adult participants. This segment holds a stronger belief in both beliefs in global citizenship through global brands and Nationalism than other three segments. Among four segments, this segment contains the highest score on their attitude toward GCCP and LCCP advertisements and their purchasing intention on brands using GCCP and LCCP. Their purchasing intention on brands using GCCP and LCCP is reflective to their attitude towards GCCP and LCCP advertisements.

The extremely nationalist holds a strong belief in consumer ethnocentrism and nationalism. This segment is; as expected that they are the most proud of their nation, their attitude toward GCCP advertisements and purchasing decision on brands using GCCP hold the lowest score among four segments.

The global-viewed adaptor believes that to be a good citizen of the country, they should consume domestic products though they are curious about foreign products. However, they do not express the high degree of nationalistic belief. Consuming domestic products is likely to be an obligation that this segment feels engaged to fulfill. As the result shows that their attitudes toward LCCP advertisements and their purchasing decision on brands using LCCP strategy hold the lowest score among four segments. This can be stated that their awareness of ethnocentric belief does not strongly reflect to their attitude toward advertisement positioning and purchasing decision. However, they are interested to try and buy global product while feeling obligated to buy local products.

The explorer segment holds a strong belief in nationalism; however less than glocal citizen and extremely nationalist. This segment does not show any outstanding score for their attitude toward GCCP and LCCP advertisement and their purchasing intention on brands using GCCP and LCCP strategies. This may imply that this segment tends to be the real explorer for trying new products from other countries.

Table 3. Glocal cultural identity clusters' attitude to GCCP and LCCP

\begin{tabular}{llllll}
\hline & \multicolumn{3}{l}{ Glocal Cultural Identity Clusters } & & F-value \\
\cline { 2 - 5 } & $(1)$ & $(2)$ & $(3)$ & $(4)$ & \\
& Explorer & Global-viewed & Glocal & Extremely & \\
& $\mathrm{n}=76$ & Adaptor & Citizen & Nationalist & \\
& $(26 \%)$ & $\mathrm{n}=54$ & $\mathrm{n}=109$ & $\mathrm{n}=58$ & \\
\hline Attitude toward GCCP ad & & $(18 \%)$ & $(37 \%)$ & $(19 \%)$ & $4.329 * *$ \\
Attitude toward LCCP ad & 4.02 & 3.76 & 4.11 & 3.45 & $4.500^{* *}$ \\
Purchasing Decision on brands using GCCP & 3.75 & 3.54 & 4.26 & 3.89 & $3.556^{*}$ \\
Purchasing Decision on brands using LCCP & 3.63 & 3.89 & 4.22 & 3.57 & $5.335^{* * *}$ \\
\hline
\end{tabular}

Note. ${ }^{*} \mathrm{p}<0.05,{ }^{* *} \mathrm{p}<0.01,{ }^{* * *} \mathrm{p}<0.001$.

\section{Discussion}

\subsection{Contributions}

This research focuses on young adult consumers' glocal cultural identity and their attitude toward consumer cultural positioning in advertising (GCCP and LCCP) and their purchasing intention on brands using GCCP and 
LCCP strategies. The research findings uncover the four segments which is reflective of the market structure of global and local brand in China: the global-viewed adaptor, the group that shows responsibility for consuming locally-made products; the extremely nationalist, the group that retains strong patriotic belief; and the glocal citizen, the group that represents young adult consumers in Net generation who are open for global world while remain preserving their local cultural identity; and the explorer, the group is still exploring their identity. Moreover, the research results also reveal the dissimilarity of an attitude toward GCCP and LCCP advertising and the dissimilarity of purchasing decision on brands using GCCP and LCCO strategies among each segments.

China is a country with a long history where people are very proud of their nation. Chinese young adult consumers who grow up under the one-child policy and the fast economic development of China, rather than being proud of nation's history, they hold a feeling of pride in the nation's economic power. Thus, they have a strong sense of nationalism and ethnocentrism. Moreover, the emphasis on the unity and uniformity in China's market leads young adult consumers' consumption pattern to be in the same direction with their cultural identity beliefs. As we can see that Chinese young adult consumers' attitude toward GCCP and LCCP advertisements are in the same direction with their global-local identity beliefs for the glocal citizen segment and the extremely nationalistic segment, no matter which glocal cultural identity segment they belong to, they are more open to global culture. It is possible that they pursue a new cultural identity from global brands to create their unique lifestyle and personal identity.

\subsection{Implications}

For brand managers of multinational and local firms, it is essential to be cognizant of an existence of the glocal cultural identity of young adult consumers in their target market especially in the emerging markets where the market segments have not yet matured. In these markets, the forming of glocal cultural identity is in the process of evolution. Each market has their unique glocal cultural identity which contains a different degree of global and local identity belief. Marketers need to figure out the proportion of the global-local cultural belief mix in the market that firm intends to enter in order to adopt the right marketing and advertising strategies to resonate with the target market.

In China, the most interesting segment for multinational firms is the glocal citizen. In terms of market size, this segment contains almost half of China's young adult consumers market which is worthwhile for multinational firms to invest the marketing money to get the market share from the local firms. We suggest the multinational firms create a message theme with deep and relevant meaning that resonate with the belief and interest of this segment to catch their attention. Multinational firms can adopt GCCP strategy by projecting a global image, while using appeals such as humor or emotion (advertising textbook, to be added later). In addition, multinational firms can cooperate with local marketers to adopt LCCP strategy and execute the positioning by adding global cultural features. We also suggest the local firms elevate their product images to global brand status by using GCCP strategy in their advertisements and creating popular phases and story theme that are relevant to hot topic or talk-of-the town in local society. If local firms succeed in providing this segment a sense of uniqueness, this segment will be a good carrier propelling local brands to global market. Moreover, using marketing messages in line with the lifestyle of this segment will help local firms achieve more loyalty from this segment who would spread positive word of mouth to their family members and peers.

For the explorer segment, which is not engaged to any cultural identity beliefs and does not utitlize global or local cultural identity to present their individual personality. They do not let the brands label who they are. This means they are exploring for the new products while forming their cultural identity. This is also an opportunity for multinational firms to grasp the market by enhancing the global cultural belief and expand the marketing channel to be more accessible. For local firms, the way to get more market share is to launch an attractive promotion campaign to let this segment understand and value more about local brands and products.

For the global-viewed adaptor segment who holds a strong ethnocentric belief, but not strong in nationalistic belief, multinational firms can promote sale volume by offering product categories or high-quality products that are unavailable in the local market. This way, this segment will have no hesitation to get the choices. As for local firms, an emphasis on promoting the idea of a responsibility to get locally-made products as a first choice is very necessary to tie this segment to the local brands and shift their loyalty pattern from "somewhat loyal" to "completely loyal".

The extremely nationalist is particularly appealing to local firms. To retain this segment's loyalty, local firms should provide premier quality brands and make inroads into global brand market share. This way, it will reinforce the sense of national pride to this segment and make them a lifelong customer of the brands. As for multinational firms intending to target this segment, joint-venture and local marketing expertise is an important 
strategy.

\subsection{Limitations and Future Research}

This study has some limitations. First, in term of sampling, the samples are from a single city which somewhat bases on the well-educated students who are likely to have more chance to associate themselves with the outside world, hence they may not proportionately represent all Chinese young adult population. Moreover, most of participants in this study are college students who depend on parents financially and whose life mainly concentrates on school. Therefore, this sample may have missed certain portion of the young adults in the country such as young professionals and young parents who just start working or have other social roles of responsibility.

Second, in terms of selection of product category and advertisement, only three brands and three categories were selected because they drew most attention from local young adults in China. However, more product categories are emerging and interesting enough to deserve consideration for future studies. Furthermore, the advertisements selected for this study were restricted by the accessibility on the internet. The brands selected, though popular among young adult consumers in China, are originally from two foreign countries: the United State and South Korea. Hence country of origin effect might cause bias among some participants. In addition, this research mainly focuses on the GCCP and LCCP advertisements, excluding FCCP advertisement since it does not frequently appear or recognized by local consumers.

This research focused solely on the global brands and products whose advertisements have been distributed globally, the results of the research provides us an understanding about the attitudes of young adults in China today's market toward advertisements of global products. Next step, to assist local brands in their pursuit of an appropriate consumer cultural positioning in advertising (GCCP or LCCP) in the global market, future research can examine Chinese brands and products that have started advertising in other parts of the world and intend to expand their global presence, and select participants from young adults in foreign countries that Chinese companies desire to enter. Finally, the future research can include other factors that influence the glocal identity among young adults such as cultural openness, cross-cultural experiences, personality-traits, consumer exposure to product advertisements, materialism, or innovativeness. Also, more brands and product categories can be included in future studies. The process of measuring attitudes towards advertisements with GCCP and LCCP can reduce more noise by eliminating the brand names, logos, colors and symbols in order to reduce impacts of strong images of the successful global brands that already deeply embedded in young adult consumers' minds.

\section{Acknowledgment}

This paper was funded by the National Natural Science Foundation of China (no. 71272026). The authors thank Vimolrat Krisanakrangkrai for assistance during the data collection process.

\section{References}

Akaka, M. A., \& Alden, D. L. (2010). Global brand positioning and perceptions: International advertising and global consumer culture. International Journal of Advertising, 29(1), 37-56. https://doi.org/10.2501/S0265048709201026

Alden, D., Steenkamp, J.-B. E. M., \& Batra, R. (1999). Brand Positioning Through Advertising in Asia, North America and Europe: The Role of Global Consumer Culture. Journal of Marketing, 63(January), 75-87. https://doi.org/10.2307/1252002

Arnett, J. J. (2002). The psychology of globalization. The American Psychologist, 57(10), 774-783. https://doi.org/10.1037/0003-066X.57.10.774

Arnould, E. J., \& Thompson, C. J. (2005). Consumer Culture Theory (CCT): Twenty Years of Research. Journal of Consumer Research, 31(4), 868-82.

Batra, R., Ramaswamy, V., Alden, D. L., Steenkamp, J. -B. E. M., \& Ramachander, S. (2000). Effects of brand local and nonlocal origin on consumer attitudes in developing countries. Journal of Consumer Psychology, 9(2), 83-95. https://doi.org/10.1207/S15327663JCP0902_3

Child, J., \& Tse, D. K. (2001). China's Transition and Its Implications for International Business. Journal of International Business Studies, 32(1), 5-21. https://doi.org/10.1057/palgrave.jibs.8490935

Coulter, R. A., Price, L. L., \& Feick, L. (2003). Rethinking the origins of product involvement, involvement with branded products, and brand commitment: Women and cosmetics in postsocialist Central Europe. Journal of Consumer Research, 30, 151-169. https://doi.org/10.1086/376809 
Dong, L., \& Tian, K. (2009). The use of Western brands in asserting Chinese national identity. Journal of Consumer Research, 36(3), 504-523. https://doi.org/10.1086/598970

Douglas, S. P., \& Craig, C. S. (2006). On improving the conceptual foundations of international marketing. Journal of International Marketing, 14(1), 1-22. https://doi.org/10.1509/jimk.14.1.1

Douglas, S. P., \& Craig, C. S. (2011). Convergence and divergence: Developing a semi-global marketing strategy. Journal of International Marketing, 19(1), 82-101. https://doi.org/10.1509/jimk.19.1.82

Eckhardt, G. M. (2006). Local branding in a foreign product category in an emerging market. Journal of International Marketing, 13(4), 57-79. https://doi.org/10.1509/jimk.2005.13.4.57

Feltham, T. S. (1994). Assessing viewer judgement of advertisements and vehicles: Scale development and validation. In C. T. Allen \& D. Roedder-John (Eds.), Advances in Consumer Research (vol. 21, pp. 531535).

Fong, V. (2004). Filial nationalism among Chinese teenagers with global identities. American Ethnologist, 31, 631-648. https://doi.org/10.1525/ae.2004.31.4.631

Hermans, H. J. M., \& Dimaggio, G. (2007). Self, identity, and globalization in times of uncertainty: A dialogical analysis. Review of General Psychology, 11(1), 31-61. https://doi.org/10.1037/1089-2680.11.1.31

Holt, D. B. (2002). Why do brands cause trouble? A dialectical theory of consumer culture and branding. Journal of Consumer Research, 29(June), 70-90. https://doi.org/10.1086/339922

Holt, D. B., Quelch, J. A., \& Taylor, E. L. (2004). How global brands compete. Harvard Business Review, 82, $68-75$.

Hung, K. H., Gu, F. F., \& Yim, C. K. (2007). A social institutional approach to identifying generation cohorts in China with a comparison with American consumers. Journal of International Business Studies, 38, 836-853. https://doi.org/10.1057/palgrave.jibs.8400288

Jensen, L. A. (2011). Navigating local and global worlds: Opportunities and risks for adolescent cultural identity development. Psychological Studies, 56(1), 62-70. https://doi.org/10.1007/s12646-011-0069-y

Kjeldgaard, D., \& Askegaard, S. (2006). The glocalization of youth culture: The global youth segment as structures of common difference. Journal of Consumer Research, 33, 231-247. https://doi.org/10.1086/506304

Lambert-Pandraud, R., \& Laurent, G. (2010). Why do older consumers buy older brands? The role of attachment and declining innovativeness. Journal of Marketing, 74(5), 104-121. https://doi.org/10.1509/jmkg.74.5.104

Özsomer, A., \& Altaras, S. (2008). Global brand purchase likelihood: A critical synthesis and an integrated conceptual framework. Journal of International Marketing, 16(4), 1-28. https://doi.org/10.1509/jimk.16.4.1

Shimp, T. A., \& Sharma, S. (1987). Consumer ethnocentrism: Construction and validation of the CETSCALE. Journal of Marketing Research, 24(3), 280-289. https://doi.org/10.1177/002224378702400304

Steenkamp, J. B. E. M., \& de Jong, M. G. (2010). A global investigation into the constellation of consumer attitudes toward global and local products. Journal of Marketing, 74(6), 18-40. ttps://doi.org/10.1509/jmkg.74.6.18

Steenkamp, J. B. E. M., Batra, R., \& Alden, D. L. (2003). How perceived brand globalness creates brand value. Journal of International Business Studies, 34, 53-65. https://doi.org/10.1057/palgrave.jibs.8400002

Strizhakova, Y., Coulter, R. A., \& Price, L. L. (2008). Branded products as a passport to global citizenship: Perspectives from developed and emerging countries. Journal of International Marketing, 16(4), 57-85. https://doi.org/10.1509/jimk.16.4.57

Strizhakova, Y., Coulter, R. A., \& Price, L. L. (2012). The young adult cohort in emerging markets: Assessing their glocal cultural identity in a global marketplace. International Journal of Research in Marketing, 29, 43-54. https://doi.org/10.1016/j.ijresmar.2011.08.002

Varman, R., \& Belk, R. W. (2009). Nationalism and ideology in an anti-consumption movement. Journal of Consumer Research, 36, 686-700. https://doi.org/10.1086/600486

Wells, W. D. (1964). EQ, son of EQ, and the reaction profile. Journal of Marketing, 28(October), 45-52. https://doi.org/10.1177/002224296402800409

Zhang, Y., Li, H., Hitt, M. A., \& Cui, G. (2007). R\&D intensity and performance of international joint ventures 
in an emerging market: Moderating effects of market focus and ownership structure. Journal of International Business Studies, 38(6), 944-960. https://doi.org/10.1057/palgrave.jibs.8400301

Zhou, L., Yang, Z., \& Hui, M. K. (2010). Non-local or local brands? a multi-level investigation into confidence in brand origin identification and its strategic implications. Journal of the Academy of Marketing Science, $38,202-218$. https://doi.org/10.1007/s11747-009-0153-1

\section{Copyrights}

Copyright for this article is retained by the author, with first publication rights granted to the journal.

This is an open-access article distributed under the terms and conditions of the Creative Commons Attribution license (http://creativecommons.org/licenses/by/4.0/). 